pathway of synthesis of this $\mathrm{C}_{40}$-compound is possibly similar to that of cholesterol in animal tissues; it may involve condensation of eight $\mathrm{C}_{6}$-acids to give a $\mathrm{C}_{48}$-compound which by six simultaneous decarboxylations gives the $\mathrm{C}_{40}$-skeleton. Prof. Mackinney's researches using leucine labelled with carbon-14 indicate that $\mathrm{C}_{4}$ of leucine is specifically incorporated into carotene by Phycomyces blakesleeanus, suggesting that leucine may form an iso- $\mathrm{C}_{3}$ unit which is incorporated into a carotenoid precursor in toto. Extended genetical studies in tomatoes suggest that the PorterLincoln series is not operative, but that the aliphatic and alicyclic carotenoids are formed in parallel from the same common precursor. Dr. M. Signol (Paris) reported the effect of tetronic acid on the pigmentation of maize seedlings. Paper chromatography shows an increase in the carotenoid hydrocarbon fraction with a disappearance in xanthophylls, chlorophyll and phæophytin; by column chromatography it was found that the major hydrocarbons were now lycopene and $\gamma$-carotene.

During the session devoted to the $B$ vitamins and vitamin $\mathbf{E}$, the oxidation of tocopherols in oils from maize and rice was discussed by Dr. G. Zwingelstein (Lyon); the tocopherols in rice are more stable than those in maize under comparable storage conditions ; thus, although initially maize has a higher tocopherol concentration, this rapidly drops to a level below that in rice. Mlle. N. Vokral (Paris), discussing the biogenesis of riboflavin by Aspergillus niger, showed that it was dependent upon the magnesium concentration of the culture medium; for example, high magnesium concentrations inhibit flavin synthesis.

Aspects of vegetable quality other than nutritional were discussed in the session on tannins and polyphenols.

In a review of anthocyanins and polyphenols (communicated), Dr. E. C. Bate-Smith (Cambridge) dealt with their relationship to appearance, flavour and texture, and described new types of those compounds which had recently been isolated from plants. Appearance and flavour of such processed vegetable products as tea and cocoa were closely connected with the polyphenol content; desirable cocoa flavour is only obtained in a cocoa bean which has been so fermented that the purple anthocyanin colour has been replaced by a brown colour of phenolic oxidation products. 'Stringiness' in beans has always been associated with lignin deposition, but recent results have indicated also the participation of leucoantho. cyanins, which are deposited during cell-wall lignification. Soluble leucoanthocyanins are responsible for hazes, sediments and 'body' of alcoholic beverages. The occurrence and identification of catechins, gallocatechins and their gallates in tea, quinic and shikimic acids ip apples and $p$-coumaroyl quinic acid in Antirrhinum were the subjects of papers by Academician A. I. Oparin (Bach Institute, Moscow), Dr. A. C. Hulme (Ditton) and Dr. H. Böhme (Berlin), respectively. Prof. J. Masquelier (Bordeaux) described the bactericidal action of certain wines which is associated with the pigmented fraction from which the sugar and the alcohol have been removed. Prof. J. Lavollay (Paris) described experiments on the coupled destruction of ascorbic acid by the action of phenolase on certain ortho-dihydroxy flavonoids. The destructive activity does not depend solely on the presence of orthodihydroxy groups since phloretin and naringenin, which do not contain such groupings, are very active. Flavonoids such as quercetin are more active as aglycones, the glycosides quercitrin and rutin being almost inactive.

In the session on mineral nutrition, Dr. D. Bertrand (Paris) gave a comprehensive review of metal enzyme systems; other papers were on the influence of mineral elements on plant growth and the effect of minerals in wheat on flour quality (Dr. W. Morgulis, Toulouse).

The proceedings of the colloquium will be published in Vol. 3 of "Qualitas Plantarum et Materiæ Vegetabiles" (Dr. W. Junk, The Hague), which it is hoped will become the official organ of the Confoederatio Internationalis ad Qualitates Plantarum Edulium Perquirendas.

J. FRIEND

\section{RESEARCH DIVISION OF THE CEMENT AND CONCRETE ASSOCIATION, WEXHAM SPRINGS}

THE Cement and Concrete Association is the research and information organization of the Portland cement industry in Britain. Its research and development station is at Wexham Springs, Stoke Poges, Buckinghamshire, where on May 1 the Minister of Works, the Right Hon. Hugh Molson, M.P., opened three new buildings.

These buildings comprise, first, a two-story block containing a printing department, canteen and selfcontained hostel with lecture theatre and recreation rooms capable of housing about forty students; secondly, a demonstration hall with an unobstructed floor space, $50 \mathrm{ft}$. $\times 10 \mathrm{ft}$., in which building techniques can be demonstrated in full scale, under cover; and thirdly, chemistry and physics laboratories.

The research station is concerned essentially with the utilization of Portland cement, problems of manufacture being studied elsewhere, and it endeavours to promote the more efficient utilization of cement, as well as finding new applications and acting as a technical service unit for all users of cement. Its activities are carried on by a staff of about twenty graduates and some eighty experimental assistants, tradesmen and labourers in five departments, covering chemistry and physics; concrete (materials and methods of preparation); structural engineering; roads and airfields; works and general services.

The Chemistry and Physics Department concerns itself with chemical and physical problems arising in concrete construction, fundamental research on the nature of hardened cement and maintenance of a standards and instrumentation section which provides facilities for making measurements and the construction of special apparatus. The pure research of the Department is directed to the elucidation of the fundamental structure of hardened cement pastes. For this purpose physical methods of analysis are mainly employed, chiefly X-ray powder photography, measurement of dielectric properties and the study of phase equilibria in the system $\mathrm{CaO}-\mathrm{SiO}_{2}-$ $\mathrm{H}_{2} \mathrm{O}$.

Applied research has embraced a range of problems some of which, such as the study of the durability of concrete exposed to weathering and chemical attack, are long-term and of indefinite duration. Others have been simple and have required only a few hours work. In this category come measurements 
of the heat capacity and thermal insulation of concrete walls and floors, and routine analytical tests to determine cement contents of concrete and identify attacking agents. The instrument section provides facilities for the servicing of electrical apparatus and undertakes the design and construction for other departments of instruments which are not available from commercial sources.

The Concrete Department is devoted to the study of the materials for making concrete and to the examination of concrete-making techniques designed to provide specific properties in the final product.

The materials section has the general objective of improving the practice of preparation of aggregates and the design of concrete mixes. To this end it studies methods of testing aggregates and cement, and of assessing the qualities required of concrete as an engineering material. Systematic investigation has enabled the factors which cause variation in quality of concrete to be identified and measured, and has made it possible to design, from widely variable raw materials, mixes which will give concrete having desired properties.

The basic research of the materials section has provided the informed background for the work of the methods section, which examines special uses of concrete and concentrates on improvements in the technique employed. A detailed study has been made of the procedure for laying granolithic floor toppings and a fundamental investigation is being made of frost damage to concrete kerbstones. As part of this work the shrinkage and creep of concrete are being examined with novel apparatus, particular attention being paid to dimensional changes in the setting and hardening period.

The Structural Engineering Department is concerned with the improvement of design methods for concrete structures, improvement of the knowledge of the behaviour of concrete structures, development of new concrete structural forms, and the study of practical constructural problems. The design studies are carried on in close collaboration with other engineering research laboratories and with practising engineers. The Department is fortunate in having available a specially designed laboratory in which tests can be made on full-scale elements of structures or on models of a size which approaches full-scale. Testing is carried out with a large test frame, the base of which is the heavily reinforced floor of the laboratory, and loading is by means of hydraulic jacks. The performance of the structure under test is examined by mechanical and electrical strain ganges and can be recorded automatically.

A special study has been made of the design of shell roofs, of the effect of concentrated loads on bridge decks and of the properties of prestressed concrete structures. The Department has also been able to collaborate with engineers on actual con. struction, and much valuable information has been obtained relating the performance of laboratory models to that realized in the full-scale structure.

The Roads Department was formed to carry out research and development work on all forms of pavement construction in which cement is used. Its principal interest has been in concrete pavements, lean concrete bases and cement-stabilized soil bases. Experimental work has been carried out on techniques of road laying and of the details of road construction, such as joint making, repair and resurfacing. The Department maintains a close interest in road and airfield work in progress, and its services are extended to site control of unusual and/or particularly important projects. Advisory work is also undertaken for local authorities and others concerned with the building of new roads.

The basic function of the Works and Services Department is the provision of a service of craftsmen and labourers for carrying out all kinds of building operations. All departments call upon the services of this Department for routine maintenance of plant and property and for the carrying out of building experiments which involve the skill of tradesmen. The Department also carries out investigations in its own right and has been particularly interested in the development of attractive surface finishes for concrete. Some hundreds of examples of different surface finishes are undergoing weathering trials on the Station, and architects and others interested in applying them are provided with detailed instructions how to achieve the effects. A further substantial part of the various work of this Department is the organization of field work for training courses. Every year training course for about forty persons are held at roughly fortnightly intervals, and one of the functions of the Works and Services Department is to arrange full-scale demonstrations of various aspects of concrete technology ranging from simple batching trials to complete demonstration of prestressing techniques.

These training courses are organized by another division of the Cement and Concrete Association, but it was felt most appropriate to hold the courses where the research work is in progress. The success of the courses and the importance attached to communication of the fruits of research are underlined by the decision to provide two of the new buildings mainly for training purposes.

\section{RESEARCH COUNCIL OF ALBERTA}

\section{REPORT FOR 1956}

$T$ HE thirty-seventh annual report of the Researeh Council of Alberta*, which includes the usual lists of publications of the Council, members of committoes, and staff, covers the year 1956, in which the formal opening of the Council's new laboratories and pilot plant on a site adjacent to the University of Alberta was the outstanding feature. The Council's geological effort was further strengthened during the year, and two new advisory committees were established, one dealing with agricultural matters and the other with the problem of hail, commencing with a study of basic cloud physics in co-operation with the Meteorological Division of the Department of Transport.

Encouraging progress was made in coal research, the major effort of the organic chemistry laboratory being concerned with the constitution of humic acids and further studies of the pyrolysis of coal in presence of acid catalysts. Comparison of the infra-red spectra of humic acids, coals and synthetic coal-like substances prepared by oxidative polymerization of hydroquinone at high temperatures suggests that while the concept of a continuous inerease of rank in coals is sound, materials giving infra-red spectra typical of bituminous coal may be found in various ways. The Physical Chemistry Laboratory has studied the mechanism of pyrolysis of coal and the * Research Council of Alberta. Thirty-seventh Annual Report, 